\title{
Dermatofibrosarcoma protuberans of the breast: A case report
}

\author{
KAMIL POHLODEK ${ }^{1}$, IVETA MEČIAROVÁ ${ }^{2}$, PETR GROSSMANN ${ }^{3,4}$ and ZDENĚK KINKOR ${ }^{3,4}$ \\ ${ }^{1}$ The Second Department of Gynecology and Obstetrics, Faculty of Medicine, Comenius University of Bratislava, \\ 82606 Bratislava; ${ }^{2}$ Alpha Medical Pathology, Ltd., 84101 Bratislava, Slovakia; ${ }^{3}$ Department of Pathology, \\ Faculty of Medicine in Plzeň, Charles University in Prague, 32300 Plzeň; \\ ${ }^{4}$ Bioptic Laboratory, Ltd., 32600 Plzeň, Czech Republic
}

Received November 5, 2016; Accepted March 6, 2017

DOI: $10.3892 / 01.2017 .6206$

\begin{abstract}
Dermatofibrosarcoma protuberans (DFSP) is a rare malignant tumor of subcutaneous tissue characterized by slow infiltrative growth. The tumor occurs in patients of all ages, with the highest frequency occurring between the second and the fifth decades of age. Genetically, DFSP is characterized by a reciprocal translocation $\mathrm{t}(17 ; 22)(\mathrm{q} 22 ; \mathrm{q} 13)$, or more often, as a supernumerary ring chromosome involving chromosomes 17 and 22. Standard treatment of a localized tumor is surgical excision with wide margins. In the present study, a case report of a 43-year-old woman with a growing tumor in the left breast is discussed. The patient underwent breast-conserving surgery. Histological and cytogenetic examinations of the tumor resulted in a diagnosis of DFSP. The clinical and morphological characteristics of the tumor, in addition to the treatment options, were also evaluated.
\end{abstract}

\section{Introduction}

Dermatofibrosarcoma protuberans (DFSP) is a rare, slow-growing, low-grade tumor of putative dermal fibroblastic origin. All DFSP recurrence is in situ and it rarely metastasizes. It usually involves the trunk and extremities, although tumors may occur in any part of the body in children and adults. The incidence rate is reported to be $\sim 5 / 1,000,000$ people annually (1-4). According to a previous study, the sex distribution is approximately equal, with a slight female predominance (4). The appearance of the tumor depends on the stage of the disease, since the tumor progresses slowly over a long period of time prior to entering a rapid growth phase (5). Genetically, DFSP is characterized by a reciprocal translocation $\mathrm{t}(17 ; 22)$ (q22;q13), or more often as a supernumerary ring chromosome involving chromosomes 17 and 22. This translocation mechanism results in the transcriptional upregulation of the platelet

Correspondence to: Dr Kamil Pohlodek, The Second Department of Gynecology and Obstetrics, Faculty of Medicine, Comenius University of Bratislava, 6 Ružinovská, 82606 Bratislava, Slovakia E-mail:kpohlodek@gmail.com

Key words: breast tumor, dermatofibrosarcoma protuberans derived growth factor subunit $\mathrm{B}(P D G F B)$ gene, in the form of a collagen type I $\alpha 1$ chain- $P D G F B$ fusion oncogene $(1,2,5)$. Patients often ignore these tumors due to their slow growth. DFSP breast involvement is rare, and is often misdiagnosed as a benign breast tumor, which delays treatment (3-5). In the present study, a case report of a woman with locally advanced DFSP of the breast is discussed.

\section{Case report}

A 43-year-old Caucasian premenopausal woman with no previous medical history was referred to the Breast Unit of the Second Department of Gynecology and Obstetrics at the University Hospital of Bratislava (Bratislava, Slovakia) in May 2016, due to the growth of a lump in the left breast. Physical examination revealed a superficial skin-infiltrating, prominent 6-cm lump located at the border of the medial quadrants of the left breast (Fig. 1). The lump was painless and not adherent to the deep layers. Mammography suggested a circumscribed round and partially lobulated radiopaque lesion with sharp contours. The patient underwent wide excision of the tumor with sentinel lymphadenectomy. Gross examination revealed a $12.0 \times 9.0 \times 8.0-\mathrm{cm}$ segment of breast tissue with an unencapsulated circumscribed $6.2 \times 6.2 \times 5.0-\mathrm{cm}$ tumor with suspicious skin infiltration. Histologically, it was defined as a low-grade mesenchymal tumor that had fish-bone arrayed spindled fibroblastic cells with low/medium nuclear polymorphism, thin-walled vessels without an epithelial component and high mitotic activity (10-12 mitotic figures/10 high-power fields). A prominent storiform cellular pattern was present (Fig. 2). The nine sentinel lymph nodes tested negative for metastases. The patient provided written informed consent with medical procedures, photographs and publication of results.

Immunohistochemical (IHC) analysis of the tumor with anti-cluster of differentiation (CD)34 (mouse monoclonal antibody; clone QBEud/10; cat. no., 790-2927; Ventana Medical Systems, Inc., Tucson, USA; ready to use; incubation time $24 \mathrm{~min}$ at $36^{\circ} \mathrm{C}$ ) and anti-CD10 (mouse monoclonal antibody; clone 56C6; cat. no., CMC11021040; Cell Marque ${ }^{\mathrm{TM}}$, Rocklin, USA; dilution 1:100; incubation time $32 \mathrm{~min}$ at $36^{\circ} \mathrm{C}$ ) was provided as specified elsewhere (5). It demonstrated positive results (Fig. 3). The tissue was negative for cytokeratins (CK) AE1/3 (anti-Pan Keratin (AE1/AE3/PCK26) primary mouse antibody; cat. no., 760-2135; Ventana Medical Systems, Inc.; 
A

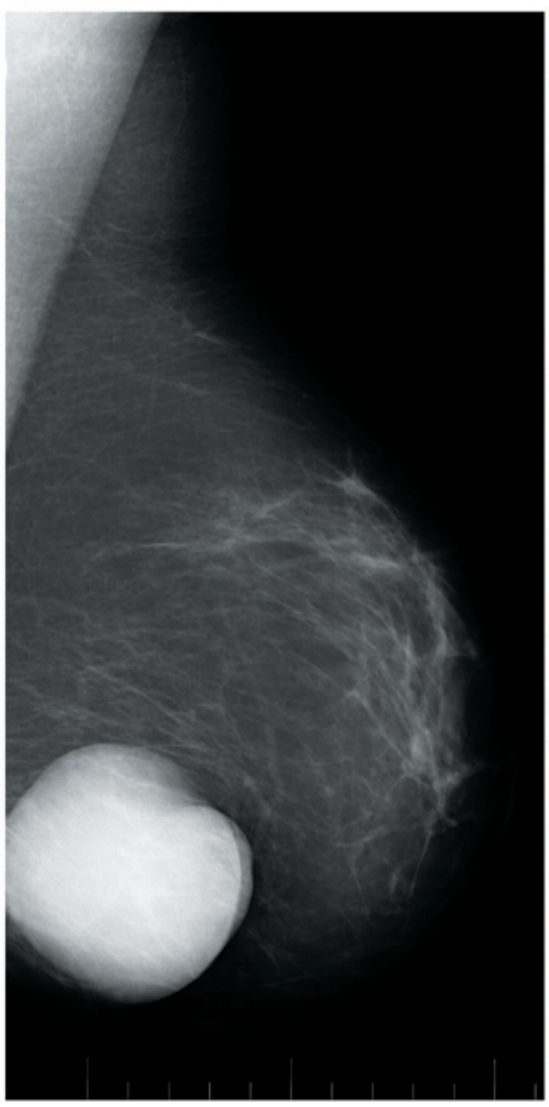

B

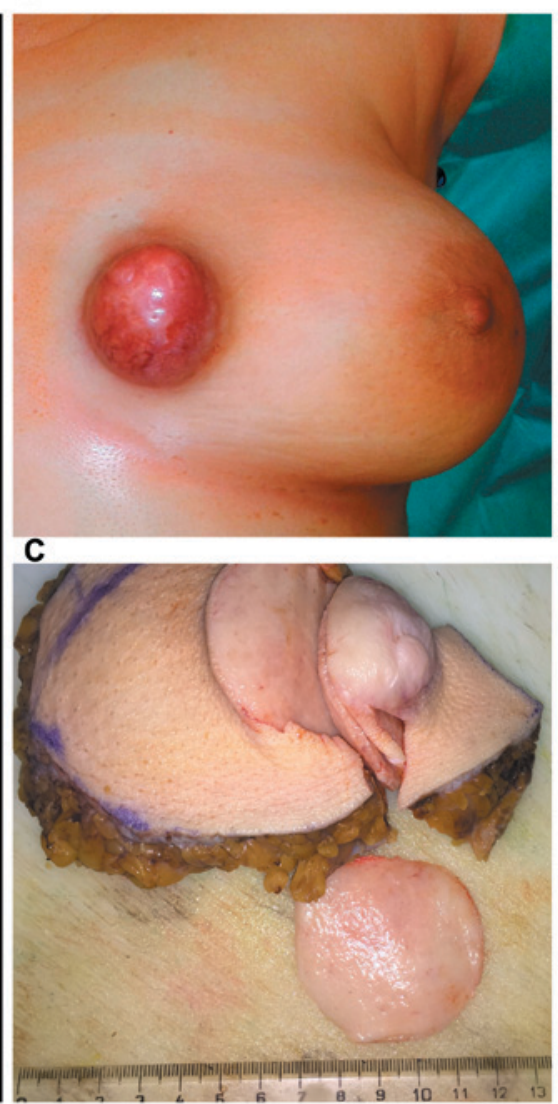

Figure 1. Dematofibrosarcoma protuberans of the breast. (A) A circumscribed round, partially lobulated radiopaque lesion with sharp contour was revealed following an X-ray digital mammography of the left breast. (B) A round tumor protruded above the surface of the skin in the medial quadrants of the left breast. (C) Gross examination revealed a 12.0x9.0x8.0-cm segment of breast tissue with a circumscribed 6.2x6.2x5.0-cm tumor, which was tan-grey colored on the cut surface.

ready to use; incubation $24 \min$ at $36^{\circ} \mathrm{C}$ ), cytokeratin 7 (Novocastra $^{\mathrm{TM}}$ liquid mouse monoclonal antibody; clone RN7; cat. no., NCL-L-CK7-560; Leica Biosystems GmbH, Nussloch, Germany; dilution 1:300, incubation $36 \mathrm{~min}$ at $25^{\circ} \mathrm{C}$ ), cytokeratins 8/18 (mouse monoclonal antibodies; clone B22.1 \& B23.1; cat. no., CMC81829040; Cell Marque ${ }^{\mathrm{TM}}$; dilution 1:500; incubation time $36 \mathrm{~min}$ at $36^{\circ} \mathrm{C}$ ), cytokeratin 19 (monoclonal mouse antibody; clone RCK108; cat. no., M0888; Dako A/S; Agilent Technologies, Inc., Santa Clara, CA, USA; dilution 1:100; incubation time $32 \mathrm{~min}$ at $36^{\circ} \mathrm{C}$ ), S100 protein (mouse monoclonal antibody; clone 4C4.9; cat. no., CMC33021050; Cell Marque ${ }^{\mathrm{TM}}$; dilution 1:200; incubation time $16 \mathrm{~min}, 36^{\circ} \mathrm{C}$ ), desmin filament (mouse monoclonal antibody; clone D33; cat. no., 243M-18, Cell Marque ${ }^{\mathrm{TM}}$; dilution 1:100; incubation time $36 \mathrm{~min}$ at $36^{\circ} \mathrm{C}$ ), epithelial membrane antigen (EMA; mouse monoclonal antibody; clone E29; cat. no., CMC24729021; Cell Marque ${ }^{\mathrm{TM}}$; dilution 1:200; incubation time $32 \mathrm{~min}$ at $36^{\circ} \mathrm{C}$ ), estrogen and progesterone receptors (rabbit monoclonal primary antibodies; clones SP1 and 1E2; cat. nos., 790-4324 and 790-2223; Ventana Medical Systems, Inc.; ready to use; incubation time $32 \mathrm{~min}$ at $36^{\circ} \mathrm{C}$ ) and cytoplasmic staining with h-caldesmon (mouse primary monoclonal antibody; clone h-CD; cat. no., M3557; Dako A/S; Agilent Technologies, Inc.; dilution 1:200; incubation time $28 \mathrm{~min}$ at $36^{\circ} \mathrm{C}$ ). In addition, the tumor was negative for apoptosis regulator B cell lymphoma-2 (anti-bcl-2 primary mouse monoclonal antibody; clone 124; cat. no., 790-4464; Ventana Medical Systems, Inc.; ready to use; incubation time $24 \mathrm{~min}$ at $36^{\circ} \mathrm{C}$ ), tumor protein p53 (anti-p53 primary antibody; clone DO-7; cat. no., 790-2912; ready to use; incubation time $32 \mathrm{~min}$ at $36^{\circ} \mathrm{C}$ ), cell surface glycoprotein CD99 (Dako CD99 mouse monoclonal antibody; clone 12E7; cat. no., M3601; Dako A/S; Agilent Technologies, Inc.; dilution 1:200; incubation time $24 \mathrm{~min}$ at $36^{\circ} \mathrm{C}$ ), cell adhesion molecule CD31 (anti-human CD31 mouse monoclonal antibody; clone JC70A; cat. no., M0823, Dako A/S; Agilent Technologies, Inc.; dilution 1:200; incubation time $36 \mathrm{~min}$ at $36^{\circ} \mathrm{C}$ ) and stem cell factor receptor CD117 (c-kit rabbit monoclonal primary antibody; clone YR145; cat. no., 117-R1; Cell Marque ${ }^{\mathrm{TM}}$; dilution 1:800; incubation time $28 \mathrm{~min}$ at $36^{\circ} \mathrm{C}$ ). The $\mathrm{IHC}$ procedures were carried out on the BenchMark XT fully-automated IHC/ISH staining slide system (Ventana Medical Systems, Inc.). The Ki67 proliferation index, evaluated according to the protocol of Knutsvik et al (6), was $10 \%$ (Fig. 3). A differential diagnosis of a solid fibrous tumor, dermatofibrosarcoma protuberans, or a spindle cell pleomorphic lipoma was considered, and the case was referred to a breast pathology specialist (Z.K.). Additional cytogenetic evaluations of collagen type I $\alpha 1$ chain $(C O L 1 A 1)$ /platelet derived growth factor subunit $\mathrm{B}$ $(P D G F B)$ gene translocation were performed (P.G.).

Fluorescence in situ hybridization (FISH). The molecular cytogenetic detection of $\mathrm{t}(17 ; 22)(\mathrm{q} 22 ; \mathrm{q} 13)$ was performed in 
A

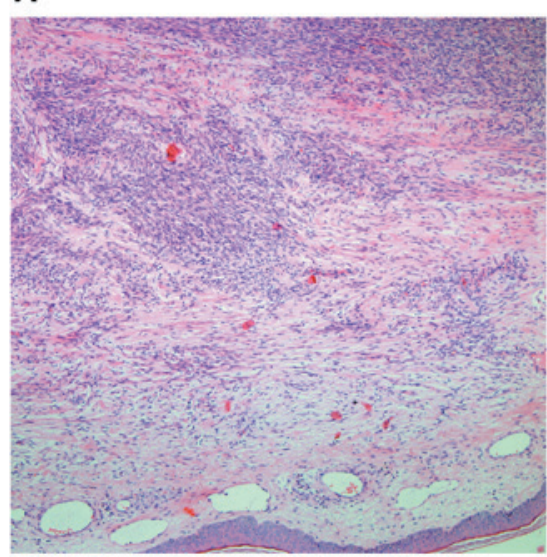

C

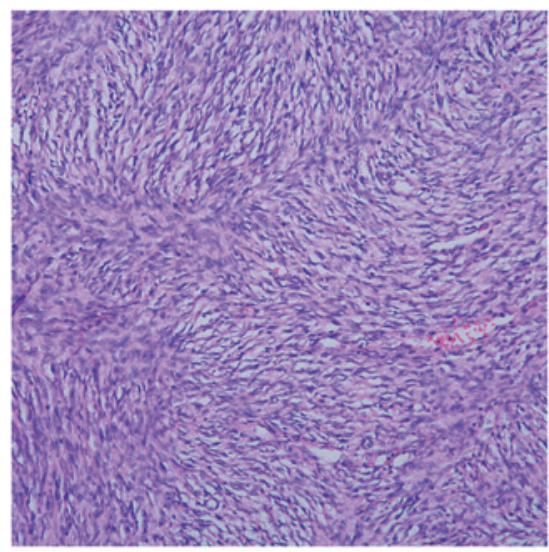

B

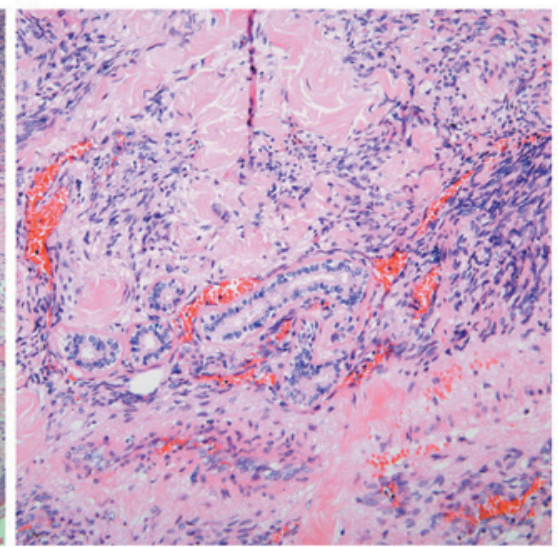

D

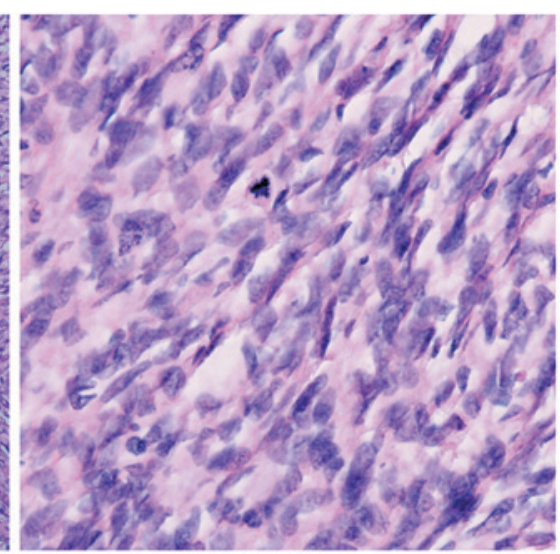

Figure 2. Hematoxylin-eosin staining of tissue from a patient with dermatofibrosarcoma protuberans of the breast. (A) Tumor growth into the skin demonstrated a zone of uninvolved dermis with chronic inflammatory infiltrate and spindle cell proliferation adjacent to the overlying epidermis (magnification, $\mathrm{x} 100$ ). (B) Tentacles of tumor surround the residual structures of the mammary glands (magnification, x200). (C) Highly cellular and tight storiform patterning of cells that are monomorphic, thin, and spindly with hyperchromatic nuclei (magnification, x200). (D) Mitotic figure without atypical mitoses (magnification, $\mathrm{x} 400$ ).

formalin-fixed paraffin-embedded (FFPE) tissues via FISH. Tissue was fixed in $10 \%$ formalin at room temperature for $24 \mathrm{~h}$. Sections of FFPE tissue measuring $4 \mu \mathrm{m}$ in thickness were placed on positively charged slides. Hematoxylin and eosin stained slides were examined to determine areas for cell counting. The unstained slides were routinely deparaffinized in xylene, incubated in 1X Target Retrieval Solution Citrate (pH 6; Dako; Agilent Technologies, Inc., Santa Clara, CA, USA) for $40 \mathrm{~min}$ at $95^{\circ} \mathrm{C}$, then digested in $0.5 \mathrm{mg} / \mathrm{ml}$ pepsin solution (Sigma Aldrich; Merck KGaA, Darmstadt, Germany) in $0.01 \mathrm{M} \mathrm{HCl}$ at $37^{\circ} \mathrm{C}$ for $25 \mathrm{~min}$. A total of $10 \mu 1$ factory premixed probes ZytoLight ${ }^{\circledR}$ SPEC COL1A1 Dual Color Break Apart Probe, ZytoLight ${ }^{\circledR}$ SPEC PDGFB Dual Color Break Apart Probe and ZytoLight ${ }^{\circledR}$ SPEC COL1A1/PDGFB Dual Color Dual Fusion Probe (ZytoVision GmbH, Bremerhaven, Germany) were applied on specimens separately. The slides were incubated using a ThermoBrite instrument (StatSpin/Iris Sample Processing, Westwood, MA, USA) at $85^{\circ} \mathrm{C}$ for $8 \mathrm{~min}$ and then $37^{\circ} \mathrm{C}$ for $16 \mathrm{~h}$. Subsequently, slides were washed in $2 \mathrm{X} \mathrm{SSC} / 0.3 \% \mathrm{NP}-40$ solution at $72^{\circ} \mathrm{C}$ for $2 \mathrm{~min}$ and counterstained with DAPI (Abbott Molecular, IL, USA). This analysis revealed COL1A1/PDGFB fusion and confirmed the diagnosis of DFSP (Fig. 4). Following extensive serial sectioning of the tumor and immunohistochemistry, no signs of malignant transformation to a low-grade fibrosarcoma were identified.
The patient has been followed up and has continued without clinical signs of disease recurrence. At the time of writing the present report, it had been $>6$ months since the initial surgery and the patient had remained disease free.

\section{Discussion}

DFSP was first described by Darier and Ferrand (7) in 1924, and was termed by Hoffmann (8) in 1925. In 1962, Taylor and Helwig (9) described, in a review of 115 cases, the histologic characteristics of the neoplasia in detail, and characterized it as a fibroblastic growth appearing as a low-grade sarcoma. DFSP typically occurs in the dermis and subcutis rather than in deeper soft tissue. Due to the rarity of breast DFSP cases, this condition is difficult to diagnose. Conventional mammography usually reveals a subcutaneous oval mass with smooth, well-defined margins (2-10). Magnetic resonance imaging (MRI) may be necessary for the localization and differential diagnosis of DFSP, and is particularly useful when primary DFSP is located in areas other than the head, neck and upper part of the thorax (10-13). Chen et al (10) described the MRI appearance of DFSP in a male breast as a well-defined lesion that has prolonged $\mathrm{T} 1$ and $\mathrm{T} 2$ relaxation times. On T1-weighted imaging, the tumor was isointense, slightly hypointense or hyperintense compared with that in skeletal muscle. In a 
A

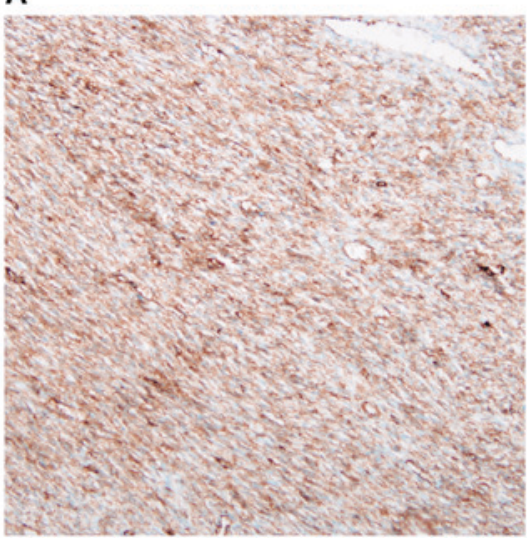

C

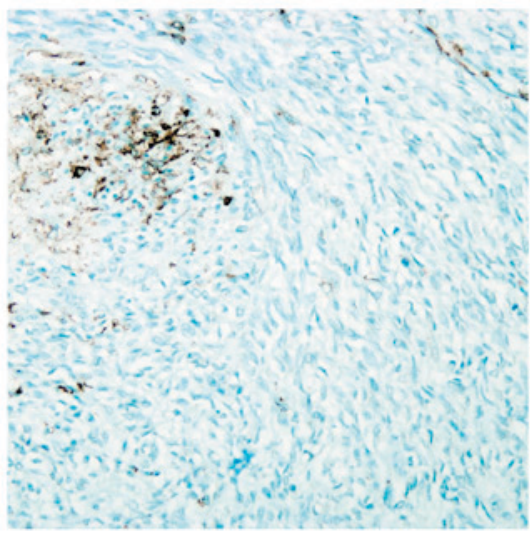

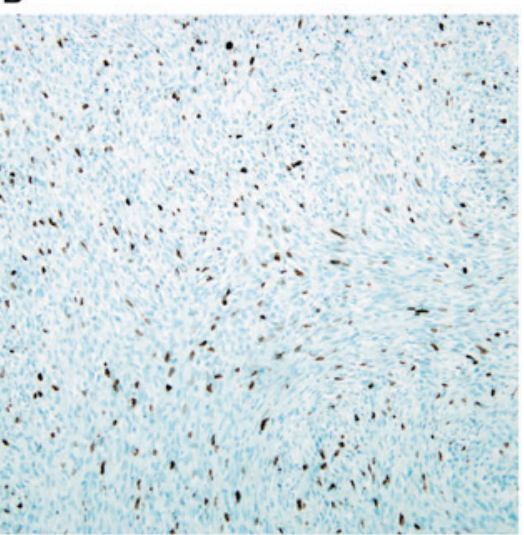

D

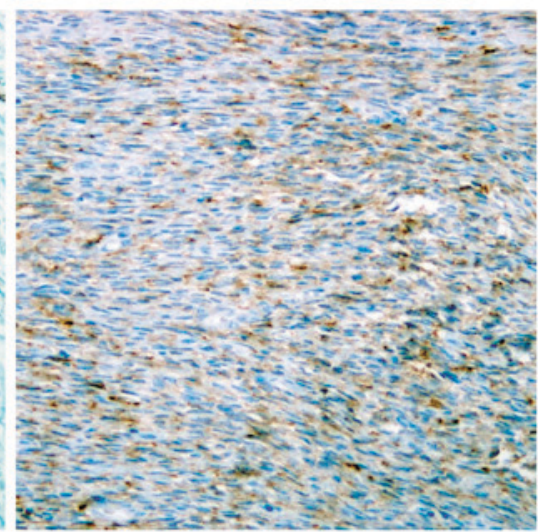

Figure 3. Immunohistochemical examination of tissue from a patient with dermatofibrosarcoma protuberans of the breast (200x). (A) Strong and diffuse staining for CD34 indicating spindle cell proliferation. (B) The index of Ki-67 proliferative activity was 10\% positive. (C) Focal weak staining for smooth muscle actin and (D) irregular weak/middle staining for CD10. CD, cluster of differentiation.

A

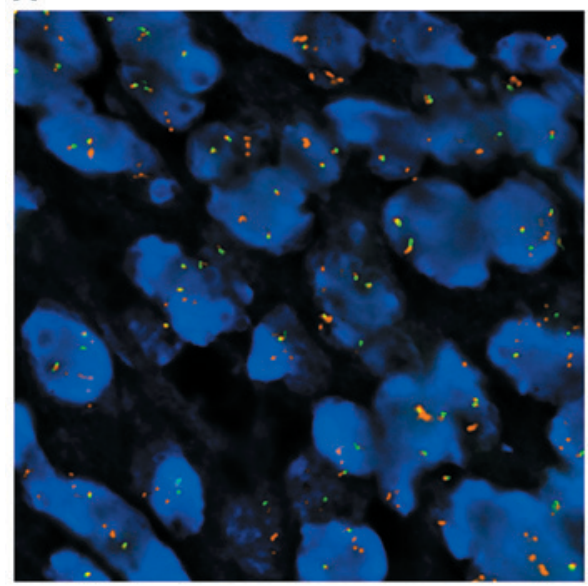

B

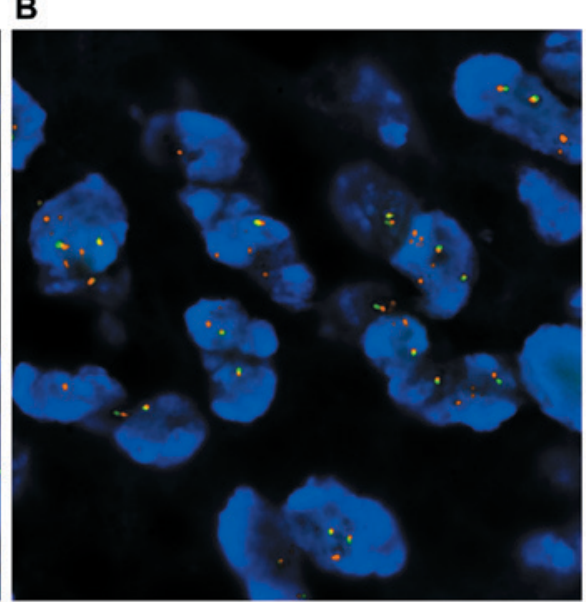

C

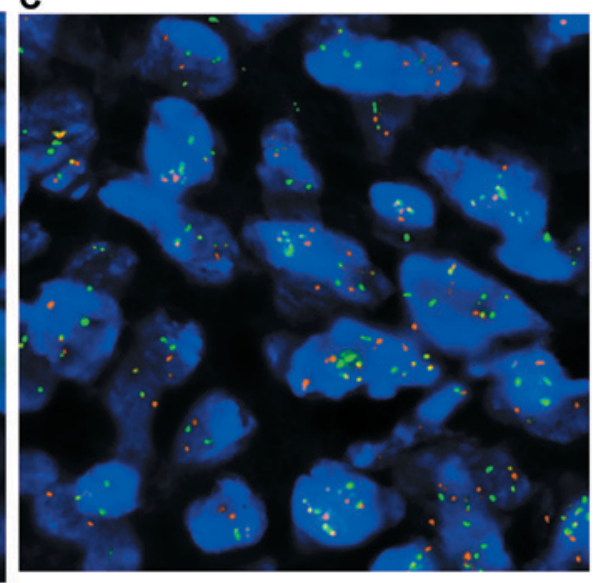

Figure 4. Detection of chromosomal translocation $\mathrm{t}(17 ; 22)(\mathrm{q} 22 ; \mathrm{q} 13)$ in paraffin-embedded tissue from a patient with dermatofibrosarcoma protuberans of the breast using gene-specific probes by FISH. (A) COL1A1 and (B) PDGFB break-apart probes: Interphase nuclei with yellow signals indicate an intact COL1A1 $(P D G F B)$ locus. Orange signals denote additional copies of an unbalanced rearranged COL1A1 (PDGFB) locus. (C) COL1A1/PDGFB dual fusion probe: FISH detects separate orange and green normal signals, and multiple yellow (orange/green) fusion signals indicate COL1A1/PDGFB translocation. PDGFB, platelet derived growth factor subunit B; COL1A1, collagen type I $\alpha 1$ chain; FISH, fluorescence in situ hybridization.

review by Millare et al (12), all 14 MRI T1-imaged lesions were demonstrated to be isointense compared with those in muscle tissue. In a study by Jiang et al (2), targeted ultrasound of the breast revealed a hypoechoic mass lesion with irregular borders and no peripheral or internal blood flow. As
DFSP metastasizes in 2-5\% of cases, extensive evaluations with computed tomography scans and laboratory tests are not usually recommended $(5,13)$. Generally, imaging results for DFSP are nonspecific, but they may aid in defining the diagnosis in an appropriate clinical setting (11-13). 
Histologic classification recognizes several subtypes of DFSP: Pigmented (Bednar tumor), giant cell fibroblastoma-like, atrophic, sclerosing, granular cell variant, fibrosarcomatous and myxoid DFSP (5). A definitive diagnosis of DFSP is usually established on the basis of routine histopathological and immunohistochemical features. Immunohistochemical expression of CD34 has been considered as a diagnostic marker for DFSP. CD34 is expressed in $80-100 \%$ of DFSP tumors $(5,8,14,15)$. Factor XIIIa is useful in the differential diagnosis between DFSP and cellular fibrous histiocytoma (15). Novel immunohistochemical markers have been identified for use in differential diagnosis, including stromelysin III, apolipoprotein D, nestin and CD163 $(5,16)$. Despite the presence of a fibrosarcomatous component in DFSP, DFSP differs from breast sarcoma in its cutaneous derivation (15-19). Fine-needle aspiration cytology has low diagnostic accuracy for mesenchymal breast tumor. Core biopsy is considered the optimal procedure for diagnosing such tumors, though adjunctive immunohistochemical analysis is often required (18-21). However, a diagnosis from a core biopsy is often difficult. The differential diagnosis of solitary fibrous tumors (SFTs) is expansive, and a diagnosis based on core biopsy specimens can be challenging, since certain distinctive features of SFT, including alternating cellular and hypocellular architecture, and vascular pattern, may not be appreciable $(15,19,21)$.

Genetically, DFSP is characterized by a reciprocal translocation $\mathrm{t}(17 ; 22)(\mathrm{q} 22 ; \mathrm{q} 13)$, or more often, as a supernumerary ring chromosome involving chromosomes 17 and 22 (21-23). These chromosomal rearrangements result in the fusion of the COL1A1 gene in chromosome bands 17q21 and 33 with the $P D G F B$ gene in chromosome $22 q 13$ (22). The main consequence of the $t(17 ; 22)(q 22 ; q 13)$ translocation is the overproduction of PDGFB by tumor cells, which leads to a constitutive activation of the PDGFB receptor, which is a type III tyrosine kinase receptor (23). The $\mathrm{t}(17 ; 22)(\mathrm{q} 22 ; \mathrm{q} 13)$ translocation can be detected either by FISH on interphase nuclei and/or by multiplex reverse transcription-polymerase chain reaction, which can be used to detect $C O L 1 A 1 / P D G F B$ fusion transcripts $(5,21-24)$.

Complete surgical resection is accepted as the optimal local treatment for DFSP. However, the minimum resection margin required to achieve local control remains undefined (25-27). When DFSP has been excised with close margins, the local recurrence rates range between 26 and $60 \%$. Following wide local excision $(2-3 \mathrm{~cm})$, reported local recurrence rates are lower (0-30\%) (25-27). Farma et al (26) suggested that with the use of a standardized surgical approach, including a meticulous pathological evaluation of margins, a low recurrence rate (1\%) was achievable with relatively narrow margins (median size, $2 \mathrm{~cm}$ ), allowing primary closure in $69 \%$ of patients. DFSP is considered to be radiosensitive, although the role of adjuvant radiotherapy in treating this neoplasm remains uncertain (28).

As mentioned above, the main consequence of the $t(17 ; 22)$ (q22;q13) in DFSP is the overproduction of PDGFB by the tumor cells, which leads to the constitutive activation of the PDGFB receptor $(5,22)$.The PDGFB receptor has tyrosine kinase activity and activates various intracellular signaling pathways $(5,21-24)$. Imatinib mesylate (STI571; Gleevec ${ }^{\circledR}$; Novartis International AG, Basel, Switzerland), a tyrosine kinase inhibitor, was used in the Imatinib Target Exploration
Consortium Study B2225 (24), where 10 assessable patients were treated with the drug. The results demonstrated that imatinib may assist in disease control in patients with locally advanced or metastatic disease. In 4 patients, imatinib therapy produced substantial regression of locally advanced tumors prior to surgical resection. However, fibrosarcomatous variants of DFSP lacking $\mathrm{t}(17 ; 22)$ may not respond to imatinib $(22,24,27,29)$. Fields et al (27) analyzed the therapy results from 244 patients with DFSP following a median follow-up of 50 months. It was concluded that primary or recurrent treatment of DFSP should be excision with negative margins, which should result in low recurrence rates and infrequent metastatic spread. Multimodality treatment, particularly the use of tyrosine kinase inhibitors, could be effective, but should not be considered as curative $(5,18,21,24-29)$. DFSP follow-ups subsequent to surgery are recommended for a minimum of 3 years, in 6-month intervals (18).

In conclusion, DFSP is a rare breast neoplasm. Despite its classification as a tumor of intermediate malignancy with a limited potential for metastasis, DFSP does possess the potential for aggressive local behavior. Complete surgical resection is accepted as the optimal local treatment for DFSP. Imatinib may assist in disease control in patients with locally advanced or metastatic disease. Due to the rare involvement of the breast in patients with DFSP, the present study reports this unique case with the clinical features and histological and cytogenetic findings.

\section{References}

1. Lemm D, Mügge LO, Mentzel T and Höffken K: Current treatment options in dermatofibrosarcoma protuberans. J Cancer Res Clin Oncol 135: 653-665, 2009.

2. Jiang J, Huang Z, Wang LH, Shen SD and Lu H: Dermatofibrosarcoma protuberans of the breast: A case report. Oncol Lett 8: 1202-1204, 2014.

3. Sin FN and Wong KW: Dermatofibrosarcoma protuberans of the breast: A case report. Clin Imaging 35: 398-400, 2011.

4. Criscione VD and Weinstock MA: Descriptive epidemiology of dermatofibrosarcoma protuberans in the United States, 1973 to 2002. J Am Acad Dermatol 56: 968-973, 2007.

5. Llombart B, Serra-Guillén C, Monteagudo C, López Guerrero JA and Sanmartín O: Dermatofibrosarcoma protuberans: A comprehensive review and update on diagnosis and management. Semin Diagn Pathol 30: 13-28, 2013

6. Knutsvik G, Stefansson IM, Azis S, Arnes J, Eide J, Collett K and Akslen L: Evaluation of Ki67 expression across distinct categories of breast cancer specimens: A population-based study of matched surgical specimens, core needle biopsies and tissue microarrays. PLoS One 9: e112121, 2014.

7. Darier S and Ferrand M: Recurrent or progressive dermatofibromas and fibrosarcoma of the skin. Ann Dermatol Venerol 5: 545-562, 1924 (In French).

8. Hoffman E: Ueber das knollentribende Fibrosarkom der Haut (dermatofibrosarcoma protuberans). Dermatol Z 43:1-286, 1925 (In German).

9. Taylor HB and Helwig EB: Dermatofibrosarcoma protuberans. A study of 115 cases. Cancer 15: 717-725, 1962.

10. Chen X, Chen YH, Zhang YL, Guo YM, Bai ZL and Zhao X: Magnetic resonance imaging and mammographic appearance of dermatofibrosarcoma protuberans in a male breast: A case report and literature review. J Med Case Rep 3: 8246, 2009.

11. Serra-Guillén C, Sanmartín O, Llombart B, Nagore E, Deltoro C, Martín I, Borella-Estrada R, Requena C, Martorell-Calatayud A, Cervera $\mathbf{J}$ and Guillén C: Correlation between preoperative magnetic resonance imaging and surgical margins with modified Mohs for dermatofibrosarcoma protuberans. Dermatol Surg 37: 1638-1645, 2011.

12. Millare GG, Guha-Thakurta N, Sturgis EM, El-Naggar AK and Debnam JM: Imaging findings of head and neck dermatofibrosarcoma protuberans. AJNR Am J Neuroradiol 35: 373-378, 2014. 
13. Zhang L, Liu QY, Cao Y, Zhong JS and Zhang WD: Dermatofibrosarcoma protuberans: Computed tomography and magnetic resonance imaging findings. Medicine (Baltimore) 94: e1001, 2015.

14. Chang GK, Jacobs IA and Salti GI: Outcomes of surgery for dermatofibrosarcoma protuberans. Eur J Surg Oncol 30: 341-345, 2004.

15. Li N, McNiff J, Hui P, Manfioletti G and Tallini G: Differential expression of HMGA1 and HMGA2 in dermatofibroma and dermatofibrosarcoma protuberans: Potential diagnostic applications and comparison with histologic findings, CD34, and factor XIIIa immunoreactivity. Am J Dermatopathol 26: 267-272, 2004.

16. Thway K, Ng W, Noujaim J, Jones RL and Fisher C: The current status of solitary fibrous tumor: Diagnostic features, variants and genetics. Int J Surg Pathol 24: 281-292, 2016.

17. Stacchiotti S, Pedeutour F, Negri T, Conca E, Marrari A, Palassini E, Collini P, Keslair F, Morosi C, Gronchi A, et al: Dermatofibrosarcoma protuberans-derived fibrosarcoma: Clinical history, biological profile and sensitivity to imatinib. Int J Cancer 129: 1761-1772, 2011.

18. Kuzel P, Mahmood MN, Metelitsa AI and Salopek TG: A clinicopathologic review of a case series of dermatofibrosarcoma protuberans with fibrosarcomatous differentiation. J Cutan Med Surg 19: 28-34, 2015.

19. Lim SZ, Ong KW, Tee Tan BK, Selvarajan S and Hoon Tan P: Sarcoma of the breast: An update on a rare entity. J Clin Pathol 69: 373-381, 2016

20. Al Barwani AS, Taif S, Al Mazrouai RA, Al Muzahmi KS and Alrawi A: Dermatofibrosarcoma protuberans: Insights into a rare soft tissue tumor. J Clin Imaging Sci 6: 16, 2016.

21. Llombart B, Monteagudo C, Sanmartín O, López-Guerrero JA, Serra-Guillén C, Poveda A, Jorda E, Fernandez-Serra A, Pellín A, Guillén C and Llombart-Bosch A: Dermatofibrosarcoma protuberans: A clinicopathological, immunohistochemical, genetic (COL1A1-PDGFB), and therapeutic study of low-grade versus high-grade (fibrosarcomatous) tumors. J Am Acad Dermatol 65 564-575, 2011.
22. Simon MP, Navarro M, Roux D and Pouysségur J: Structural and functional analysis of a chimeric protein COL1A1-PDGFB generated by the translocation $\mathrm{t}(17 ; 22)(\mathrm{q} 22 ; \mathrm{q} 13.1)$ in dematofibrosarcoma protubrans (DP). Oncogene 20: 2965-2975, 2001.

23. Giacchero D, Maire G, Nuin PA, Berthier F, Ebran N, Carlotti A, Celerier P, Coindre JM, Esteve E, Fraitag S, et al: No correlation between the molecular subtype of COL1A1-PDGFB fusion gene and the clinicohistopathological features of dermatofibrosarcoma protuberans. J Invest Dermatol 130: 904-907, 2010.

24. McArthur GA, Demetri GD, van Oosterom A, Heinrich MC, Debiec-Rychter M, Corless CL, Nikolova Z, Dimitrijevic S and Fletcher JA: Molecular and clinical analysis of locally advanced dermatofibrosarcoma protuberans treated with imatinib: Imatinib target exploration consortium study B2225. J Clin Oncol 23: 866-873, 2005

25. Snow SN, Gordon EM, Larson PO, Bagheri MM, Bentz ML and Sable DB: Dermatofibrosarcoma protuberans: A report on 29 patients treated by Mohs micrographic surgery with long-term follow-up and review of the literature. Cancer 101: 28-38, 2004.

26. Farma JM, Ammori JB, Zager JS, Marzban SS, Bui MM, Bichakjian CK, Johnson TM, Lowe L, Sabel MS, Wong SL, et al: Dermatofibrosarcoma protuberans: How wide should we resect? Ann Surg Oncol 17: 2112-2118, 2010.

27. Fields RC, Hameed M, Qin LX, Moraco N, Jia X, Maki RG, Singer $S$ and Brennan MF: Dermatofibrosarcoma protuberans (DFSP): Predictors of recurrence and the use of systemic therapy. Ann Surg Oncol 18: 328-336, 2011.

28. Williams N, Morris CG, Kirwan JM, Dagan R and Mendenhall WM: Radiotherapy for dermatofibrosarcoma protuberans. Am J Clin Oncol 37: 430-432, 2014.

29. Eilers G, Czaplinski JT, Mayeda M, Bahri N, Tao D, Zhu M, Hornick JL, Lindeman NI, Sicinska E, Wagner AJ, et al: CDKN2A/p16 Loss implicates CDK4 as a therapeutic target in imatinib-resistant dermatofibrosarcoma protuberans. Mol Cancer Ther 14: 1346-1353, 2015. 